\title{
Efeito do extrato de alga e da argila silicatada na severidade da alternariose e na produtividade da cebolinha comum (Allium fistulosum L.)
}

\author{
Isaac B. Araújo ${ }^{1}$, Luiz A.M. Peruch ${ }^{2} \&$ Marciel J. Stadnik ${ }^{1}$ \\ ${ }^{1}$ Departamento de Fitotecnia, CCA, Universidade Federal de Santa Catarina, Cx. Postal 476, 88040-900, Florianópolis, SC; \\ ${ }^{2}$ Epagri / Estação Experimental de Urussanga - Unibave / Núcleo PACA, Rod. SC 446, Km16, s/n, bairro Estação, Cx. Postal \\ 49, 88840-000, Urussanga, SC
}

Autor para correspondência: Luiz A. M. Peruch, e-mail: lamperuch@epagri.sc.gov.br

\begin{abstract}
RESUMO
A alternariose é uma das doenças mais importantes da cebolinha em cultivo orgânico. Assim, o objetivo deste trabalho foi avaliar o efeito de pulverizações semanais de argila silicatada (Rocksil ${ }^{\circledR}$ ) e extrato de Ulva fasciata no controle da doença e produtividade da cebolinha neste sistema de cultivo. Avaliou-se a severidade final e a área abaixo da curva de progresso da doença nas folhas centrais (Yf e AACPDf), bem como da planta inteira (Yp e AACPDp). Na colheita, determinou-se o comprimento e peso fresco das folhas. O experimento foi repetido em quatro ciclos da cultura. Os dados de severidade da doença e produtividade foram submetidos à análise de variância e teste de Duncan $(P \leq 0.05)$. Na maioria dos ciclos experimentais, diferenças significativas foram verificadas na sanidade e produtividade dos tratamentos em relação à testemunha (plantas tratadas com água). Ambos preparados propiciaram reduções médias de 41 a $62 \%$ na severidade final (Yf e Yp) e de 28 a 58\% na área abaixo da curva de progresso da doença (AACPDf e AACPDp). Os tratamentos das plantas com argila silicatada e extrato de alga aumentaram o peso fresco das folhas em média de $46 \%$ e $32 \%$, respectivamente. Apesar deste trabalho indicar que a argila silicatada e o extrato de algo têm potencial para o controle da alternariose da cebolinha, mais estudos são necessários para elucidar os níveis de controle desses tratamentos em diferentes condições edafoclimáticas.

Palavras-chave: Alternaria porri, cultivo orgânico, extrato de algas, pó de rocha
\end{abstract}

\begin{abstract}
Effect of seaweed extract and silicate clay on Alternaria leaf spot and on the yield of green onion (Allium fistulosum L.)

Alternaria leaf spot is one of the most important diseases of green onion in organic farming. The objective of this study was to evaluate the effect of weekly sprays of silicate clay $\left(\right.$ Rocksil ${ }^{\mathbb{}}$ ) and extract of Ulva fasciata in disease control and yield of the green onion in organic farming. Final disease severity and area under the disease progress curve were evaluated on central leaves (Y1 and AUDPCl) as well as the whole plant (Yp and AACPDp). Length and fresh weight of leaves was determined at harvest. The experiment was repeated in four crop cycles. Data on disease severity and yield were subjected to analysis of variance and Duncan test $(\mathrm{P}<0.05)$. In most of the experimental cycles, significant differences were observed in the sanity and yield of the treatments compared to the control (plants treated with water). Overall, both preparations reduced the final disease severity (Yf and Yp (by 41-62\% ) and the AUDPCs by $28-58 \%$. Treatments of plants with silicate clay and seaweed extract increased the fresh weight of leaves by $46 \%$ and $32 \%$, respectively. Although this study indicates that silicate clay and seaweed extract have the potential for disease control, further studies are needed to elucidate the control levels of these treatments in different edaphoclimatic conditions.
\end{abstract}

Key words: Alternaria porri, organic system, silicate clay, seaweed extract

A cebolinha comum (Allium fistulosum L.) é uma planta condimentar muito apreciada no Brasil. É uma espécie considerada perene, que tem folhas cilíndricas e fistulosas, apresentando perfilhamento e formação de touceira. A colheita se dá por meio de cortes que se iniciam entre 55 e 60 dias após o plantio ou entre 85 e 100 dias após a semeadura, quando as folhas atingem em torno de 0,20 a $0,40 \mathrm{~m}$ de altura. Geralmente, o rebrotamento da cebolinha é aproveitado para novos cortes, podendo um cultivo ser explorado por dois ou mais anos, com vários ciclos de produção, principalmente quando são conduzidos em condições de clima ameno (Filgueira, 2000).
A alternariose, também conhecida por mancha púrpura, é uma doença amplamente disseminada, causa perdas severas em aliáceas cultivadas em regiões tropicais e subtropicais, e representa uma das principais doenças da cebolinha em cultivos orgânicos. É causada pelo fungo Alternaria porri (Ellis) Cif., que infecta e necrosa as folhas de espécies do gênero Allium, tais como A. cepa (cebola), A. sativum (alho) e $A$. fistulosum (cebolinha) (Wordell Fillho et al., 2006).

O corte baixo e a eliminação dos restos culturais doentes são os métodos empregados no controle da alternariose da cebolinha (Pereira \& Homechin, 1996). 
Não existe nenhum fungicida registrado para essa cultura em razão de não ser explorada em larga escala. Além disso, em virtude do ciclo curto da planta, a pulverização de agroquímicos para o controle de doenças da cebolinha pode ser considerada problemática devido aos resíduos poderem permanecer nas folhas comercializáveis.

$\mathrm{Na}$ agricultura orgânica se dá ênfase a tecnologias de baixo impacto ambiental. Há algum tempo, preparados diversos vêm sendo empregados no combate de pragas e doenças de várias culturas. Estas substâncias alternativas podem envolver múltiplos princípios de controle, tais como a nutrição vegetal e a indução de resistência. O uso de extratos vegetais, resíduos organo-minerais e biofertilizantes é uma prática frequentemente aplicada pelos produtores orgânicos catarinenses no controle de pragas e doenças (Oltramari et al. 2002), muitas vezes, no entanto, sem comprovação científica sobre sua eficiência.

O equilíbrio nutricional é um dos principais fundamentos que norteiam a agricultura orgânica. Segundo Chaboussou (1995), plantas nutricionalmente equilibradas têm condições de se defender melhor contra seus patógenos. Mais recentemente, o papel do silício na fisiologia das plantas vem sendo estudado com maior atenção e seu uso aplicado no controle de doenças. Embora não seja considerado um elemento essencial às plantas, o silício pode reduzir consideravelmente os danos provocados por doenças e pragas de importância econômica, diminuindo drasticamente a necessidade de aplicação de agroquímicos (Alvarez \& Datnoff, 2001). Existem vários produtos à base de silício no mercado que podem ser utilizados na agricultura orgânica. Nas plantas, o silício participa no fortalecimento da camada de células epidérmicas, formando barreira física contra a penetração das hifas dos fungos (Marschner, 1995). Em espécies acumuladoras de silício, tais como o trigo, foi verificada a redução do número de lesões e área abaixo da curva de progresso da doença pelo uso de silicato de cálcio (Xavier Filha et al., 2011). Resultados positivos foram obtidos pela pulverização com silicato de sódio e silicato de potássio no controle da antracnose do feijoeiro (Moraes et al., 2006) e da ferrugem da soja (Pereira et al., 2009), respectivamente.

Os extratos de algas também estão sendo avaliados quanto à sua capacidade de controlar doenças de plantas. Os modos de ação desses extratos geralmente são diversos, podendo atuar pela melhora da nutrição vegetal, por antibiose e/ou por indução de resistência (Abreu et al., 2008; Paulert et al., 2009). Além do uso consagrado como fertilizantes, algumas espécies de algas produzem moléculas bioativas capazes de estimular processos fisiológicos e induzir resistência em plantas (Stadnik \& Paulert, 2008). Por exemplo, extratos da macroalga verde Ulva fasciata Delile podem atuar através da ativação de mecanismos de resistência controlando diferentes tipos de doenças fúngicas, tais como a antracnose do feijoeiro (Abreu et al., 2008; Paulert et al., 2009), o míldio e a antracnose da videira (Galvão et al., 2006) e a mancha foliar de Glomerella na macieira (Araujo et al., 2008). O polissacarídeo ulvana presente no extrato é considerado o composto responsável pela indução de resistência (Cluzet et al., 2004, Paulert et al., 2009).

O objetivo deste trabalho foi avaliar o efeito do extrato da alga Ulva fasciata e da argila silicatada no controle da alternariose da cebolinha sob cultivo orgânico em condições de campo.

Os experimentos foram conduzidos em quatro ciclos de rebrote das parcelas e em uma área de produção orgânica certificada da empresa Cheiro Verde em Florianópolis, SC (S 27 31' 12"'- O 48 28' 12"; altitude: $20 \mathrm{~m}$ ), no período de setembro/2005 a fevereiro/2006.

As mudas de cebolinha foram produzidas em bandejas de isopor contendo composto orgânico comercial Plantmax a partir de sementes da cultivar cebolinha verde (Isla Sementes Ltda., Porto Alegre - RS). Aos 15 dias após a semeadura, as mudas foram transplantadas em canteiros a céu aberto com solo tipo argissolo que apresentava as seguintes características químicas: $\mathrm{pH}$ 6,9, MO 4,0\%, P 90 ppm, K 291 ppm, Al 0,0 cmolc/dm ${ }^{3}, \mathrm{Ca} 4,4 \mathrm{cmolc} / \mathrm{dm}^{3}$ e $\mathrm{Mg} 2,3 \mathrm{cmolc} / \mathrm{dm}^{3}$. $\mathrm{O}$ sistema de irrigação foi do tipo aspersão. $\mathrm{O}$ espaçamento utilizado foi de $30 \times 15 \mathrm{~cm}$ entre plantas As adubações foram efetuadas com esterco de aves curtido no momento do preparo do solo. O controle das ervas espontâneas foi efetuado semanalmente pela capina e arranquio manual.

O delineamento experimental foi inteiramente casualizado com quatro repetições. As parcelas foram compostas por seis filas de plantas com uma área de $2,5 \mathrm{~m}^{2}$, sendo que o experimento totalizava $30 \mathrm{~m}^{2}$. Nos experimentos foram testados os seguintes tratamentos: argila silicatada $(1 \%, \mathrm{p} / \mathrm{v})$, extrato de alga Ulva fasciata $(0,5 \%$, $\mathrm{v} / \mathrm{v}$ ) e testemunha (água). A argila silicatada (Rocksil ${ }^{\circledR}$ ) foi fornecida pela empresa Lia-Ulmasud (Taguatinga Sul, DF), apresentando a seguinte composição média: 20\% $\mathrm{Al}_{2} \mathrm{O}_{3}, 17,43 \% \mathrm{SiO}_{2}, 9,82 \% \mathrm{~S}, 1,31 \% \mathrm{CaO}, 0,34 \% \mathrm{TiO}_{2}$, $0,18 \% \mathrm{MgO}, 0,16 \% \mathrm{Fe}_{2} \mathrm{O}_{3}, 0,10 \% \mathrm{P}_{2} \mathrm{O}_{5}$. O extrato da alga foi preparado de acordo com Abreu et al. (2008) pelo método de extração alcoólica através dos seguintes passos: colheita e secagem da alga; extração em um recipiente com álcool:água na proporção de 1:1 por sete dias no escuro; separação da parte sólida e líquida, descartando-se a sólida; banho-maria $\left(50^{\circ} \mathrm{C}\right)$ até o volume do líquido reduzir-se ao volume sólido inicial para obtenção da solução padrão. As pulverizações foram realizadas em intervalos semanais, iniciando-se após sete dias do corte (colheita) das plantas das parcelas. Em cada etapa de rebrote foram realizadas quatro pulverizações dos tratamentos.

Os produtos testados foram inicialmente diluídos em água na concentração adequada, efetuando-se as aplicações com um pulverizador costal com bico cone cheio com volume de calda de $300 \mathrm{~mL} / \mathrm{m}^{2}$. O início das pulverizações e o intervalo entre as mesmas seguiram um calendário fixo nas quatro fases do experimento.

A doença se desenvolveu naturalmente no local, onde o inóculo do patógeno era abundante. A severidade 
Efeito do extrato de alga e da argila silicatada na severidade da alternariose e na produtividade...

da doença nas folhas foi avaliada com auxílio de uma escala diagramática composta de cinco notas de severidade: $1 \%, 5 \%, 20 \%, 50 \%$ e $80 \%$ (Azevedo, 1997). A doença foi avaliada em cinco plantas por parcela atribuindo-se uma nota para o seu aspecto geral e outra para a severidade em três folhas centrais, com auxílio da escala diagramática. Foram efetuadas quatro avaliações em intervalos de sete dias a partir da segunda semana de condução de cada ciclo da cebolinha. Os dados de severidade na planta (Yp=planta) e nas folhas centrais ( $\mathrm{Yf}=$ folhas centrais) foram usados para calcular as respectivas áreas abaixo da curva de progresso da doença, AACPDp e AACPDf. Para tanto, utilizouse a fórmula: AACPD $=\sum\left(y_{i}+y_{i+1}\right) / 2 . d_{t i}$, sendo $y_{i}$ e $y_{i+1}$ os valores de severidade observados em duas avaliações consecutivas e $\mathrm{d}_{\mathrm{ti}}$ o intervalo entre as avaliações (Shaner \& Finney, 1977). A AACPDp foi determinada pela avaliação visual da severidade em todas as folhas e a AACPDf foi calculada pela média de três folhas centrais marcadas em cada planta.

Ao final de cada ciclo, determinou-se o comprimento final das folhas. Para isso, mediu-se com auxílio de uma régua o comprimento entre a base e a ponta de três folhas de cinco plantas por parcela, antes da colheita. A produtividade de cada parcela foi avaliada após o corte raso (aprox. $2 \mathrm{~cm}$ do solo) das cinco plantas, determinando-se o peso fresco em balança digital com precisão de $\pm 1 \mathrm{~g}$.

As variáveis avaliadas foram submetidas à análise de variância e as médias comparadas pelo teste de Duncan $(P \leq 0.05)$.

Os tratamentos afetaram significativamente a sanidade e a produtividade da cebolinha nos quatro ciclos da cultura. Foram verificadas diferenças significativas entre os tratamentos em relação AACPD e severidade final da alternariose nas folhas e plantas na maioria dos ciclos experimentais (Figura 1 e 2).

Considerando a AACPD, pulverizações semanais do extrato da alga propiciaram uma redução média de $50 \%$ na doença, tanto na planta inteira (AACPDp) como nas folhas centrais (AACPDf). A argila silicatada, por sua vez, reduziu em média 40\% essas variáveis em comparação à testemunha, porém somente na etapa conduzida em setembro foi estatisticamente diferente da testemunha quanto à AACPDf (Figura 1).

Considerando a porcentagem final de área necrosada por A. porri, as pulverizações semanais como o extrato da alga reduziram em média $70 \%$ a severidade da doença na planta inteira (Yp) e na folha (Yf), em comparação à testemunha, sendo significativamente superior em três dos quatro ciclos experimentais. Somente no ciclo conduzido em janeiro não foram verificadas diferenças estatisticamente significativas. A argila silicatada apresentou desempenho um pouco inferior ao extrato de alga, mas com severidades médias 50\% menores que a testemunha (Figura 2).

Quanto à produtividade, os tratamentos com argila silicatada ou extrato de alga causaram incrementos no comprimento e peso fresco das folhas. Contudo, o comprimento final das folhas foi afetado significativamente apenas na primeira etapa, quando ganhos de 5 e 19\% foram verificados para ambos os tratamentos. $\mathrm{O}$ incremento médio desta variável nos quatro ciclos do experimento foi de 11 e 12\% para extrato de alga e argila silicatada, respectivamente. Os pesos frescos das folhas, por sua vez, foram significativamente superiores em dois ciclos. $\mathrm{O}$ aumento médio proporcionado pelo extrato de alga foi de $32 \%$ e de $46 \%$ para argila silicatada.

Silicatos têm sido empregados com relativo sucesso no controle de doenças. Exemplos do seu emprego auxiliando no aumento de resistência dos tecidos vêm sendo estudados em vários patossistemas (Alvarez \& Datnoff, 2001; Moraes et al., 2006, Pereira et al., 2009). Silicato de sódio, de cálcio e de potássio são alguns dos compostos já empregados no controle de doenças (Moraes et al. 2006). Neste experimento, as pulverizações de argila silicatada, que apresenta um alto conteúdo de silício (17,9\% $\mathrm{SiO}_{2}$ ), beneficiaram a sanidade e o crescimento da folha da cebolinha (Figura 3).

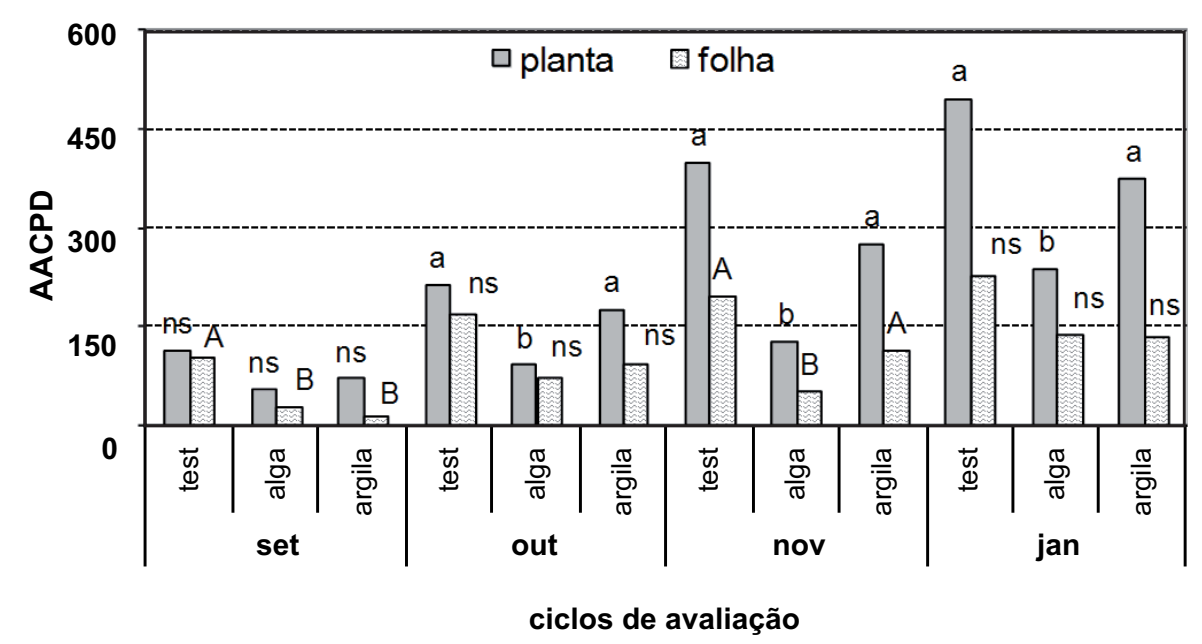

Tropical Plant Pathology 37 (5) September - October 2012
FIGURA 1 - Efeito da pulverização de extrato de alga e argila silicatada na área abaixo da curva de progresso da doença da planta inteira (AACPDp) e da folha marcadas (AACPDf), em plantas de cebolinha (Allium fistulosum L.) infectadas por Alternaria porri, durante quatro ciclos de produção em Florianópolis, SC. Colunas seguidas pela mesma letra, dentro de cada ciclo não diferem significativamente pelo teste de Duncan $(P<0,05)$. 
I.B. Araújo et al.

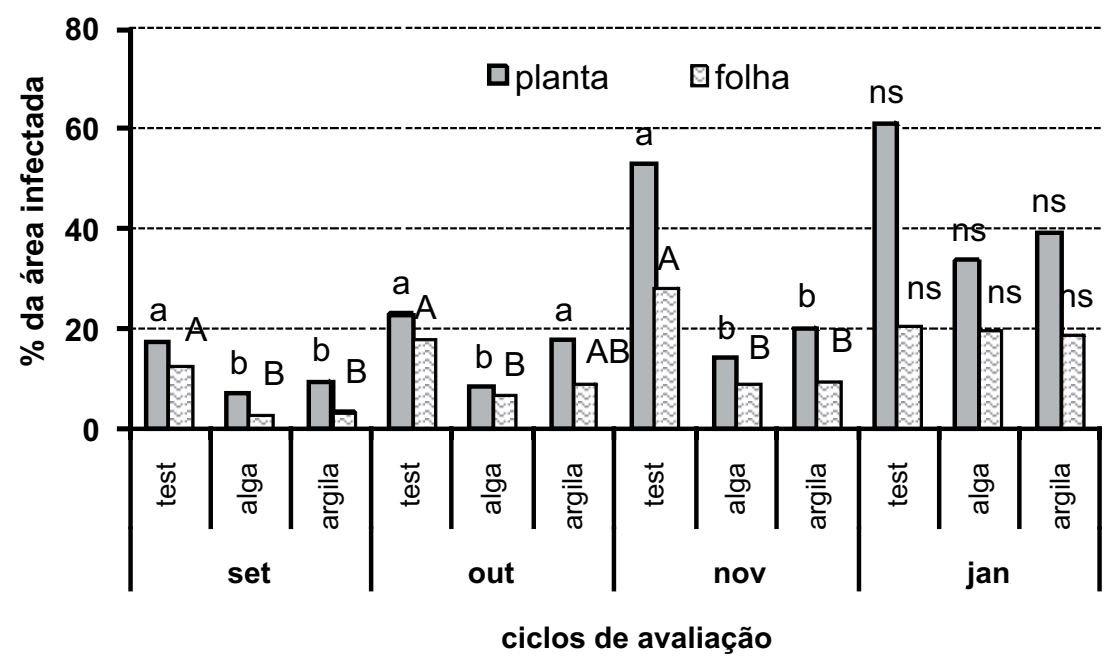

FIGURA 2 - Efeito da pulverização de extrato de alga e argila silicatada na severidade final da alternariose (Alternaria porri) em planta inteira (Yp) e em folhas marcadas (Yf) de plantas de cebolinha (Allium fistulosum L.) em cada ciclo do experimento em Florianópolis, SC. Colunas seguidas pela mesma letra, dentro de cada ciclo, não diferem significativamente pelo teste de Duncan $(P<0,05)$.

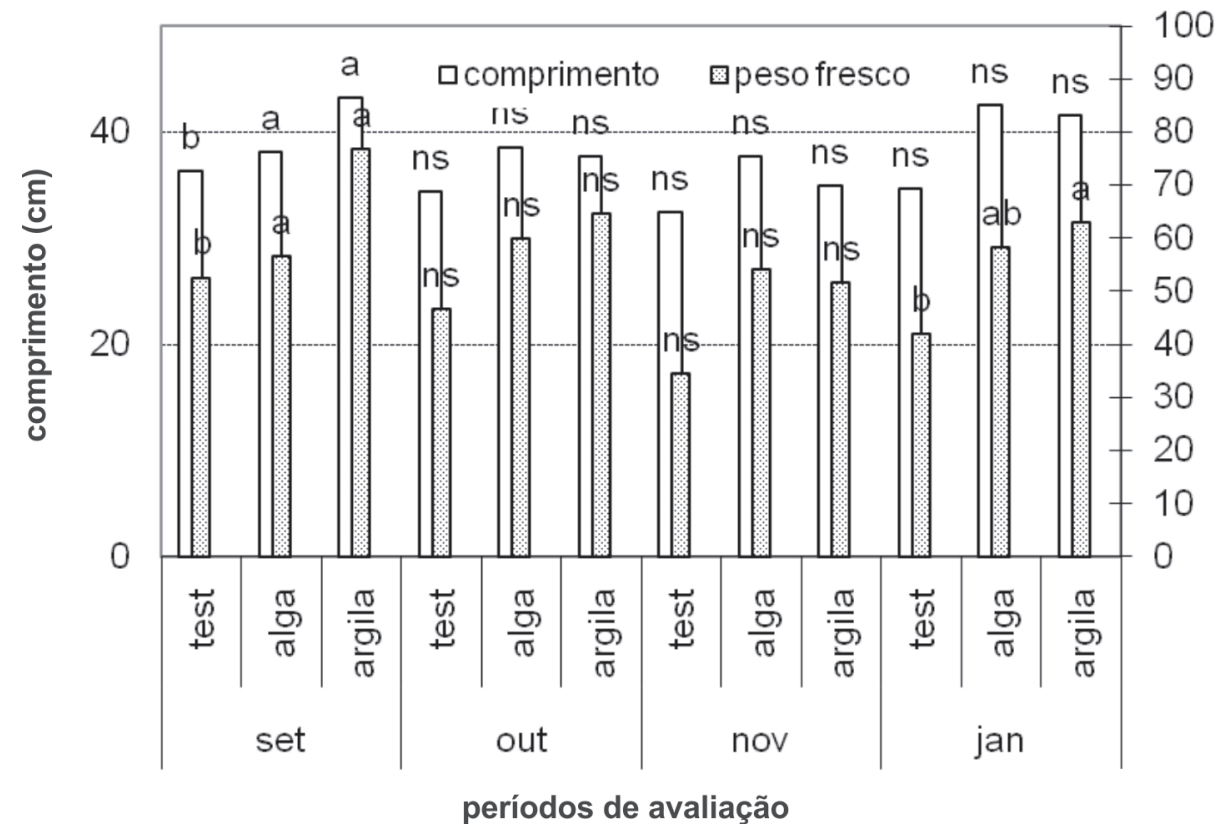

FIGURA 3 - Efeito da pulverização de extrato de alga e argila silicatada no comprimento $(\mathrm{cm})$ e peso fresco $(\mathrm{g})$ de folhas de cebolinha (Allium fistulosum L.) em quatro ciclos de colheita em Florianópolis, SC. Colunas seguidas pela mesma letra, dentro de cada ciclo, não diferem significativamente pelo teste de Duncan $(P<0,05)$.
A argila silicatada propiciou, de forma geral, menores valores de AACPD e de severidade final quando comparados à testemunha, mas com pouca diferença em relação ao extrato da alga. As possíveis discrepâncias de efeito dos tratamentos devem estar relacionadas a fatores ambientais e/ou pressão de inóculo que resultaram em diferentes intensidades de doença, especialmente na última etapa dos experimentos. Neste caso, considera-se que as barreiras físicas e químicas associadas ao fator de nutrição mineral podem não ter sido suficientemente eficientes, como já verificado em outros patossistemas (Moraes et al., 2006). Aplicações de caldas preparadas com rochas moídas para fins de controle de doenças são raramente encontradas na bibliografia, mas os resultados obtidos neste trabalho indicam seu potencial de uso, especialmente em sistemas orgânicos.
Os ganhos de rendimento avaliados pelo comprimento e peso fresco das folhas também foram verificados para argila silicatada. A utilização de rochas moídas para fertilização de solos tem sido aplicada por produtores em diversas culturas com aumento de produtividade. O efeito do extrato da alga sobre o comprimento e peso fresco das folhas poderia ser devido ao fornecimento de nutrientes pela pulverização semanal dos extratos e/ou pelo efeito bioestimulante.

Além do uso tradicional consagrado como fertilizantes orgânicos, as algas apresentam um enorme potencial biotecnológico na obtenção de compostos bioestimulantes e/ou fitoprotetores. Estes usos mais recentes possibilitam uma utilização mais racional destes recursos naturais, pois aumentam seu valor de mercado e são usados em menor quantidade por área, quando comparados aos fertilizantes (Stadnik \& Paulert, 2008). Além de acumularem

Tropical Plant Pathology 37 (5) September - October 2012 
Efeito do extrato de alga e da argila silicatada na severidade da alternariose e na produtividade...

expressivamente macro e micronutrientes $(\mathrm{N}, \mathrm{Ca}, \mathrm{K}, \mathrm{Fe}, \mathrm{Cu}$, etc), as algas marinhas são importantes fontes de diversos compostos biologicamente ativos (Michalak \& Chojnacka, 2009; Stadnik \& Paulert, 2008). Por exemplo, a pulverização desse extrato algal estimula a fisiologia e aumenta o peso seco de plantas de feijão em aproximadamente $20 \%$. Por outro lado, o polissacarídeo ulvana, que não tem efeito antimicrobiano, é capaz de reduzir a severidade da antracnose em 38\% (Paulert et al., 2009).

Ulva spp. são algas frequentes e abundantes em todo o litoral brasileiro, podendo por isso, ser uma fonte potencial para utilização em extratos. Assim como neste experimento, onde foi verificado que o extrato dessa alga tem efeito sobre Alternaria porri, existem registros anteriores do uso de $U$. fasciata em diferentes patossistemas, com reduções médias de doenças variando de 50 a 70\% (Stadnik \& Talamini, 2004; Cluzet et al., 2004; Galvão et al., 2006; Abreu et al., 2008; Paulert et al., 2009).

Em suma, pulverizações semanais de extrato de alga Ulva fasciata e de argila silicatada podem auxiliar no controle da alternariose (Alternaria porri) e no incremento da produtividade da cebolinha (Allium fistulosum) em sistema de cultivo orgânico. Contudo, em alguns dos ciclos experimentais conduzidas em épocas distintas, esses tratamentos não afetaram significativamente a severidade da doença e/ou produtividade das plantas. Portanto, mais estudos são necessários para elucidar os níveis de controle desses tratamentos em diferentes condições edafoclimáticas.

\section{REFERÊNCIAS BIBLIOGRÁFICAS}

Abreu GF, Talamini V, Stadnik MJ (2008) Bioprospeç̧ão de macroalgas marinhas e plantas aquáticas para o controle da antracnose do feijoeiro. Summa Phytopathologica 34:22-26.

Alvarez J, Datnoff LE (2001) The economic potential of silicon for integrate management and sustainable rice production. Crop Protection 20:43-48.

Azevedo LAS (1997) Manual de quantificação de doenças de plantas. São Paulo SP. Novartis.

Chaboussou F (1995) Plantas doentes pelo uso de agrotóxicos: A teoria da trofobiose. 2. ed. Porto Alegre RS. L\&PM.

Cluzet S, Tonegrossa C, Jacquet C, Lafitte C, Fournier J, Mercier L, Salamagne S, Briand X, Esquerré-tugayé MT, Dumas, B (2004) Gene expression profiling and protection of Medicago truncatula against a fungal infection in response to an elicitor from green algae Ulva spp. Plant, Cell and Environment 27:917-928.

Filgueira FAR (2000) Novo manual de olericultura: Agrotecnologia moderna na produção e comercialização de hortaliças. Viçosa MG. Editora UFV.

Galvão S, Stadnik MJ, Peruch LAM, Bruna E.D (2006) Avaliação da eficiência de produtos alternativos para o controle do míldio e da antracnose em videiras (var. Niágara Branca). Agropecuária Catarinense 19:91-93.

Marschner H (1995) Mineral nutrition of higher plants. 2 ed. San Diego CA. Academic Press.

Michalak I, Chojnacka K (2009) Edible macroalga Ulva prolifera as microelemental feed supplement for livestock: The fundamental assumptions of the production method. World Journal of Microbiology and Biotechnology 25:997-1005.

Moraes SRG, Pozza EA, Alves E, Pozza AAA, Carvalho JG, Lima $\mathrm{PH}$, Botelho AO (2006) Efeito de fontes de silício na incidência e severidade da antracnose do feijoeiro. Fitopatologia Brasileira 31:69-75.

Oltramari AC, Zoldan P, Altmann R (2002) Agricultura orgânica em Santa Catarina. Florianópolis SC. Instituto Cepa.

Paulert R, Talamini V, Noseda M, Smânia A, Stadnik MJ (2009) Effects of sulfated polysaccharide and alcoholic extracts from green seaweed Ulva fasciata on anthracnose severity and growth of common bean (Phaseolus vulgaris L.). Journal of Plant Diseases and Protection 116:263-270.

Pereira SC, Rodrigues FA, Carré-missio V, Oliveira MGA, Zambolim L (2009) Aplicação foliar de silício na resistência da soja à ferrugem e na atividade de enzimas de defesa. Tropical Plant Pathology 34:164-170.

Pereira RAS, Homechin M (1996) Efeito do modo e época de colheita das folhas de cebolinha (Allium fistulosum) na incidência do fungo Alternaria spp.. Semina Ciências Agrárias 17:40-44.

Shaner G, Finney RE (1977) The effect of nitrogen fertilization on the expression of slow-mildewing resistance in Knox wheat. Phytopathology 67:1051-1056.

Stadnik MJ, Paulert R (2008) Uso de macroalgas marinhas na agricultura. Série Livros do Museu Nacional do Rio de Janeiro 30:267-279.

Wordell Filho JA, Rowe E, Gonçalves PAS, Debarba JF, Boff P, Thomazelli LF (2006) Manejo fitossanitário na cultura da cebola. Florianópolis SC. Epagri.

Xavier Filha MS, Rodrigues FA, Domiciano GP, Oliveira HV, Silveira PR, Moreira WR (2011) Wheat resistance to leaf blast mediated by silicon. Australasian Plant Pathology 40:28-38. 